\title{
INVESTIGATING THE IMPACT OF ONLINE LEARNING ON ENGINEERING STUDENTS' SOCIALIZATION EXPERIENCES DURING THE PANDEMIC
}

\author{
Juliette Sweeney, Qin Liu, Greg Evans \\ University of Toronto \\ juliette.sweeney@mail.utoronto.ca
}

\begin{abstract}
The global shift to online learning prompted by the COVID-19 pandemic has accentuated how learning online alters postsecondary students' socialization experiences and learning outcomes. In December 2020, a large Canadian engineering faculty surveyed its undergraduate students to assess their learning experiences in the exclusive online environment during the pandemic. This paper used qualitative data from the survey, as complemented by descriptive quantitative results, to explore how the online environment impacted engineering students' socialization processes and their perception of learning. Using Weidman's model of socialization, this paper contributes to better understandings of the individual and particularly environmental factors that have influenced engineering students' socialization processes while they learn online during the pandemic, and the importance of social interactions to student learning in engineering education.
\end{abstract}

Keywords: online learning, socialization, perception of learning, COVID-19 pandemic

\section{INTRODUCTION}

In response to the COVID-19 pandemic, Canadian postsecondary institutions and instructors had to pivot rapidly to adapt pedagogical methods to online environments in spring 2020. The online delivery mode continued throughout the academic year of 2020-2021. The shift to online learning precipitated by the pandemic dramatically altered how postsecondary students are taught and socialized. For programs that were not typically offered online before the pandemic, like engineering, all the changes made to accommodate the online environment have affected the teaching and learning practices in numerous ways. This paper focusses on changes that students encountered in communication and interaction and how these changes impacted their socialization and perception of learning.

For this purpose, we use Weidman's model of student socialization within professional schools [6] to examine how online environments impact students' socialization and learning. Weidman defines socialization as "the processes through which individuals gain the knowledge, skills and values necessary for successful entry into a professional career requiring an advanced level of specialized knowledge and skills" [6]. Applying this definition to engineering education, socialization can be viewed as the process that provides engineering students with both the knowledge and skills needed to become an engineer, as well as the norms, ethics and values of the profession.

Our analysis reveals how engineering students' socialization processes changed in reaction to the dramatically different educational environment during the pandemic and how these changes have impacted students' perceptions of learning, which we conceived as the outcome of socialization in this study. This paper contributes to better understandings of the individual and particularly environmental factors that influenced engineering students' socialization processes while they learned online during the pandemic, and the importance of social interactions to student learning.

\section{LITERATURE REVIEW}

Literature on online learning has shifted its focus since early 2020, when both the scale and scope of online education have grown exponentially. This was driven by COVID-19 public health measures in Canada, which required postsecondary institutions to turn online learning that was previously an option for the minority of students into a mandated direction for all postsecondary students. Prior to the pandemic, online learning literature focused on online learners who are older adults and mostly have fulltime jobs and families $[1,38,39]$. Studies examining the differences and similarities between traditional classroom and online learning in higher education find that online courses have lower retention rates [9], that learning styles and individual identities influence how students learn in online environments [10], and that online environments can polarize academic performance [11]. Research studying how online environments affect students' socialization and social integration in colleges and 
universities has reported that the lack of in-person orientation or frosh sessions has impacted first year students' abilities to form relationships with other students [4], that less accessibility to visual cues in online environments means students have fewer ways to establish and maintain social connections [15], and that the use of mobile devices in asynchronous online discussions increases the level of interactions amongst students [16]. Other studies focused on the pedagogical practices within online learning environments [12-14] that best support successful social integration of students. In contrast, online learning research since early 2020 has focused on practices within single sites that facilitated online teaching models in emergency situations $[4,5]$. Online learning has been seen to increase accessibility by transcending geography $[3,18]$ or offering students greater control over the way other students perceive them [2]. It was also noted that a unilateral shift to the online environment reduces accessibility by deepening the digital divide [3, 18].

Literature also shows that an online learning environment adds more asynchronous communication and makes communication more prone to anonymity, which bring both advantages and disadvantages to interpersonal interactions. While the asynchronous communication during online learning allows students more time to consider and reflect on their responses, it also removes non-verbal behavior of social markers, such as clothing and physical appearance; and students with verbal difficulties who write adequately are able to communicate asynchronously with others comfortably and fluently [2]. Some research finds students resist specific asynchronous communication methods, with online discussion forums being particularly unpopular as students perceive them as a waste of time [1]. While some students miss the ebb and flow of in-person social interactions, other students experience far less social stress and are more likely to ask questions because of the relative anonymity of online environments [4] and greater student control over when and how asynchronous material is learned [2]. It was also found that the anonymity of online communication may also decrease students' sense of belonging [17].

\section{CONCEPTUAL FRAMEWORK}

In this study, we used Weidman's socialization model to help understand the socialization processes and their outcomes. Weidman's work is grounded in the "college impact" research which examines how students are impacted by the postsecondary education institutions they attend and the experiences they have within them [7]. Challenging earlier research that was primarily psychologically oriented, Weidman positioned his socialization model as being sociologically oriented rather than focused on individuals, and directed toward understanding the structural nature of socialization processes that occur within universities. As structural elements of socialization are under the control of postsecondary institutions, he expected the resulting research to be potentially more "policy relevant" to them $[7,8]$.

Following an input-environment-output (I-E-O) model, Weidman's model recognized two sources of influence on students' socialization processes $[6,7,8]$. One is the personal background characteristics of the student, including their social class, academic ability, and predisposition (i.e., the Input). The other source represents the social patterns of influence affecting students' socialization, including the organizational, academic and extra-curricular dimensions of the learning environment (i.e., the Environment); and students' linkages to these dimensions. At the centre of the model is the core socialization experience, consisting of the normative context of the academic program, socialization processes (interaction, integration, learning), and core elements (knowledge acquisition, investment, and involvement). Three mechanisms occur in the socialization processes: firstly, interactions with others; secondly, integration with the expectations of peers and faculty; and thirdly, the required acquisition of knowledge and skills for professional practice. The interactions can be both formal and informal, and reveal to students the academic and professional norms that students are expected to internalize in order to integrate and comply with the expectations of their peers and faculty, to a greater or lesser extent. Within the socialization processes, there are various reference groups that are internal (such as peers and faculty) and external (such as family and non-college peers) to the university. Further, the socialization processes shape both student experience and student outcomes, such as career choice, personal values, sense of belonging, and identification with a profession (i.e., the Output).

Weidman's framework was first used in 1989 to describe the socialization of undergraduate students [8], and expanded in 2001 to recommend best practices for the effective socialization of graduate and professional students [6]. It was also used in 2003 to examine how doctoral students become socialized to academic norms [26] and in 2016 to conceptualize the socialization of students of colour in graduate programs [7]. While our study did not focus on career choice or development of professional identity as student outcomes, Weidman's framework was relevant as it reveals the influencing factors of students' socialization in postsecondary education settings and addresses how socialization processes can impact student outcomes.

In light of Weidman's model, we asked these research questions to guide our inquiry:

- During the pandemic, how did the learning environment change so as to potentially impact students' socialization processes? 
- How do engineering students socialize in the online environment? What are the characteristics of the socialization processes?

- How do the socialization processes impact engineering students' perception of their learning in the online environment?

\section{METHODS}

The data source for this paper was a home-designed survey that was distributed to undergraduate engineering students at a large Canadian engineering faculty in December 2020, right after all courses were delivered online in an academic semester. A total of 503 students completed the survey, generating a response rate of $10 \%$; an additional 156 students answered some of the survey questions. The survey mainly asked students about their perceptions of online teaching practices and their online learning experiences. The respondents represented students in all years of study and all engineering programs of the faculty. Of the respondents, $48 \%$ were men, and $50 \%$ women; $76 \%$ domestic, and $24 \%$ international students. The research project, of which the survey was a part, received approval from the university's office of research ethics.

This paper drew upon the results from descriptive analysis of the total responses to Likert-scale questions and thematic analysis of the student comments for four openended questions in the survey. These questions asked student participants to explain how online teaching strategies were helpful or unhelpful to their learning; activities outside of class that helped them learn; and the impact of the online environment on their learning.

\section{FINDINGS}

We organize the findings into two sections: (1) the changed learning environment; and (1) socialization processes and their impact on learning.

\subsection{The Changed Learning Environment}

This section presents the findings addressing the first research question. Our data suggested that many instructors adjusted their teaching methods to fit the changed educational environment. Table 1 shows that the vast majority of the respondents (84-94\%) reported that their instructors used teaching techniques, such as synchronous and asynchronous teaching, recorded live class sessions, and used an inverted classroom approach, in the online environment. While we do not have data to indicate how widely these teaching techniques were used in in-person environment, it is reasonable to expect that these techniques had not been used so frequently prior to the pandemic and thus that the learning environment changed dramatically.
Table 1. Teaching techniques used in the online environment

\begin{tabular}{|c|c|}
\hline Teaching Techniques & $\begin{array}{c}\text { Having } \\
\text { been Used }\end{array}$ \\
\hline $\begin{array}{l}\text { Instructor recorded live class sessions and } \\
\text { then posted them for student use at their } \\
\text { discretion. }\end{array}$ & $94 \%$ \\
\hline $\begin{array}{l}\text { [Inverted classroom approach] Instructor } \\
\text { posted material (i.e., pre-recorded lecture } \\
\text { and readings) prior to the class and used } \\
\text { live class sessions for discussion, } \\
\text { questions and active learning activities. }\end{array}$ & $92 \%$ \\
\hline $\begin{array}{l}\text { [Synchronous teaching] Instructor did all } \\
\text { the teaching through live class sessions }\end{array}$ & $90 \%$ \\
\hline $\begin{array}{l}\text { Instructor stayed active on online } \\
\text { discussion forum (e.g., Piazza). }\end{array}$ & $89 \%$ \\
\hline $\begin{array}{l}\text { [Asynchronous teaching] Instructor } \\
\text { posted course material for students to } \\
\text { view at their own time, without any live } \\
\text { class sessions. }\end{array}$ & $88 \%$ \\
\hline $\begin{array}{l}\text { Instructor assigned students to breakout } \\
\text { groups in live class sessions. }\end{array}$ & $84 \%$ \\
\hline Instructor had live office hours. & $82 \%$ \\
\hline
\end{tabular}

The changed learning environment affected student experiences in multiple ways, and, more often than not, brought additional challenges to many students. Overall, $33 \%$ of the respondents found the impact of the online instruction on their learning to be positive whereas $48 \%$ rated the impact as negative. Specifically, the vast majority of the respondents perceived a higher academic workload in online learning than taking classes in person $(81 \%)$, reported having adjusted their learning strategies when learning online (84\%), and felt less motivated to learn in the online environment (79\%). Over two-thirds perceived a substantial challenge in managing screen fatigue, participating in extra-curricular activities, and learning while having less interaction with peers, all of which students could have managed with less difficulty in an inperson environment. In addition, $18-28 \%$ of the respondents perceived a substantial challenge in accessing online learning.

\subsection{Socialization Processes and Their Impact on Learning}

To address the second and third research questions, our analysis identified six themes about engineering students' socialization processes in the changed learning environment and their impact on student learning.

Theme 1. New patterns of interactions influenced student engagement in learning activities. 
The online environment spawned a significant decrease in verbal communication in informal settings as a student commented, "There isn't opportunity to really verbally communicate anymore because a lot of things are done over text chat or email." Even when it came to verbal communication, all interpersonal interactions had to take place virtually behind the screen of a computer or another electrical device. This means interactions often became anonymous and were less likely to rely on visual cues due to the options of turning on or off the microphones or cameras on the online communication tools, such as Zoom or Microsoft Teams.

Our data show that during the live class sessions, an emerging norm of students having cameras and microphones switched off, either by student choice or by instructor request, considerably affected the effectiveness of breakout room discussions. Only $28 \%$ of students found breakout groups a helpful teaching strategy. Some complained that certain patterns of communication among peers became a barrier.

Breakout rooms for students to discuss class material were often discouraging as more often than not nobody in the breakout rooms would turn on their microphones, cameras or participate through the chat. It would just be 5 or ten minutes of complete silence until we were called back to the main room.

I really did not enjoy the breakout rooms in Zoom classes. Often times in our own home we do not come prepared to have group meetings with cameras on so they can catch you off guard. Also, a large number of students just leave when breakout rooms are announced so a Break out a room of 8 can very easily just become one or two people.

On the other hand, anonymity appeared to help increase engagement for some students, as the following quote explains. Of the total respondents, 50\% agreed that it was easier and safer to ask questions in an online environment.

I am too shy to raise my hand in a class but it was much easier to type any questions I had to the professor.

Theme 2. Decreased interpersonal interactions affected student learning in terms of acquiring engineering knowledge and setting career goals.

The exclusive online learning environment during the pandemic limited the frequency of interpersonal interactions. Many students found it difficult to interact with instructors and $45 \%$ of students perceived the online environment having a negative impact on their ability to seek help and guidance. As shown in the following quotes, students reported decreased interactions with both peers and instructors, during formal class sessions and in extracurricular activities such as club participation. This unfavorable situation hindered students from acquiring engineering knowledge and skills and clarifying their career direction when they needed to.

A big challenge was not having other students around in classes to directly ask questions or even interact with socially... labs were also more difficult because you couldn't just go to the computer lab and find other students working on the same thing to ask questions. The lack of in person extra-curriculars was also difficult for me because it meant my life was much less balanced than in previous years.

I was part of 2 design clubs in second year and this year I only participated in 1 because the experience was much less enjoyable. Even for the 1 I was a part of, it was harder to work together and collaborate.

I can no longer meet and interact with some students and professors that I was hoping to. Especially specialized professors who could give me career advice.

Theme 3. Lack of social interactions affected students' mental well-being they would need to learn well.

While $90 \%$ and $80 \%$ of the respondents felt support from peers and instructors, some students found that the exclusive online environment exacerbated students' feelings of social isolation, especially for lower-year students. As suggested by the quotes below, the sense of alienation affected students' abilities to persevere and maintain their motivation to learn.

Very hard to persevere without the support of friends/the feeling of joint experience... it's easy to feel alienated, especially when struggling with deadlines/content. (first-year student)

It was nearly impossible to make new friends because we never interact with other students...I don't even know what other people in my class look like. It feels super lonely and that is my biggest barrier to learning online...It's hard to get time with the professor or TAs as well because students can't overhear or add on to other's questions. (second-year student)

Theme 4. Students better appreciated synchronous interactions, despite increased opportunities for asynchronous communication in the online environment.

The online learning space saw an increased use of asynchronous interactions due to the parallel use of synchronous and asynchronous online instruction. 
Asynchronous interactions enhanced the timing flexibility of communication, particularly for students who lived in time zones remote to Toronto, but also caused delays and errors in communication in some instances.

When asked what teaching strategies were helpful to their learning, a greater proportion of the respondents favoured those that involved live class sessions, recording live class sessions, and live office hours (respectively $69 \%$, $84 \%$ and $77 \%$ rated helpful or very helpful) than completely asynchronous teaching (50\%). The following quotes showed that students preferred the immediacy of having questions answered "in the moment" and the pacing in synchronous teaching and a live office hour session that was adjusted to the students' comprehension.

Live teaching sessions was best since I was able to ask questions on the spot. The instructor also paused to ensure all students understood the concepts. The pace was dependent on students' response like in-person classes.

Office hours were a great time to ask personal questions about homework and conceptual information.

In addition, studying with friends outside of class, as an informal way of peer interaction, was the most popular learning activity, with $88 \%$ of the respondents finding it a helpful or very helpful. Some upper-year students managed to schedule time with professors for more personal interactions, as the quote below shows. All this means that spontaneous, informal interactions with peers and instructors retained its importance to students in the online environment.

[It helped] having individual or group zoom meetings with the prof to check in (not office hours but a meet and greet for marks) because it was a chance to talk to the prof about other things. (fourth-year student)

Theme 5. The online environment was not short of opportunities for students to socialize and learn from others.

Despite the challenges the online environment presented for interpersonal interactions, instructors attempted to create opportunities for students to interact with each other. These opportunities included breakout room discussion during live class sessions, group projects as assignments, and discussion forums outside of the class. The following quotes suggested that when these mechanisms worked effectively, they facilitated student learning.

Team breakout rooms to work on in lecture problems. This was helpful because I could bounce my ideas off of other people and complement or change them accordingly.

I enjoyed group projects on the content because it allowed me to work with my peers on the content of the course (which is difficult in the online setting).

Piazza, discussion boards with quick replies because it opened a clear communication line with the professor, TAs, as well as other students.

Further, the challenges in social interactions in the online environment seemed to have "pushed" a small number of students, at least, to improve on their communication skills when working online, including managing online communication, empathizing with others, and online teamwork, as the following quotes suggested.

In that sense I developed skills related to online team meetings and online project management, and I had to get better at communicating online, but I feel like I would have developed those skills if I needed to use them in a work setting regardless.

I think the online learning experience helped me develop a stronger sense of compassion for other people. It also forced me to become more social and approachable.

It affected my personal development probably equivalently to how it would in any other semester. The only big difference was working with others, as I had to strategize new ways to get group work done.

Theme 6. Personal dispositions affected students' ways of interacting with others.

In their comments, some students explicitly linked personality types or learning styles to their perceptions of the online environment and learning. Some students who described themselves as social or extrovert voiced a preference for in-person learning whereas others who were shy or introverted indicated their preference for online learning. Two students stated:

Seeking help is easier because of the anonymity aspect. I find many feel embarrassed to ask question in person, or shy to do so in front of crowds, both... are not issues when taking an online course.

As a very social person this year has been extremely hard. I do well in environments where I can socialize with people and ask questions in person. 


\section{DISCUSSION}

The online learning environment during the pandemic has disrupted many norms for both instructors and students, who continue to adapt to the new norms emerging from the online learning environment. Many elements in our findings align with existing literature. For example, the significant increase in using asynchronous methods in online instruction and impacts of online learning on students' increased feelings of social isolation and deteriorating mental health were also reported by surveys at other universities [18, 23, 24]. Similarly, other research $[2,5]$ also shows that online learning allows students to use text messages to communicate with others more frequently, thus increasing their ability to ask questions and receive feedback. Further, our data confirmed earlier research showing that lack of visual clues and being asynchronous in virtual communication interfere with students' ability to communicate and decrease the quality of interpersonal interactions $[1,14,15,19]$.

Going beyond confirming the previous findings, this paper elucidates how engineering students socialize when learning online during the pandemic. Overall, our findings demonstrate that the exclusive online environment gave rise to new patterns of interpersonal interactions; engineering students had to, either reactively or proactively, respond to the new normative context for learning; and the emerging online socialization processes, in turn, affected students' perception of their learning. While our analysis focused on data collected from students of a single engineering faculty, our findings can arguably reflect student experiences in other engineering faculties as well.

In light of Weidman's socialization model, our analysis showed social patterns of influence that affected engineering students' socialization when learning online. One source of influence related to certain aspects of an online environment, such as greater chances for being anonymous and asynchronous in communication, which conditioned how individuals could interact with each other. Our data showed that some students took advantage of these aspects to become more engaged with classmates while others chose to withdraw from interacting. The other source of influence concerned the teaching strategies that instructors started to use, or chose to use more frequently, for online instruction. These teaching strategies shaped students' learning activities and how students could learn as part of a community. While increased use of asynchronous teaching tended to delay interpersonal communications, instructors did try to maintain venues, such as online breakout rooms, group projects and live office hours, for spontaneous interactions that would occur in an in-person environment.

Better understandings of these structural aspects of socialization processes help identify what to improve to address the existing challenges. Regarding the influence from the online environment itself, it is important to raise the awareness among engineering students about the constraints and affordances of an online learning environment and help them to strategically tackle the challenges related to virtual communication so they can learn how to interact with others effectively when nonverbal cues are absent. Our data showed that some students were able to work this out themselves; however, effective online communication remained a substantial challenge for many students. Therefore, we recommend that online socialization be integrated into engineering communication courses. To address the influence from online pedagogies, engineering instructors need to be purposefully mindful of the opportunities that allow students to interact with each other in their courses and make efforts to optimize these opportunities by increasing the frequency and quality of social interactions. To achieve this in breakout groups and online teams, we recommend that instructors keep the same membership in student groups throughout the term, increase the number of checkins from instructors or TAs, and provide clear instructors for deliverables.

Weidman's model guided us to examine socialization processes from three perspectives: interactions, integration and learning. As shown in the identified themes in the previous section, the data gathered by our survey mainly informed how engineering students interacted and learned but offered little information specific to students' integration. This can be seen as a limitation of our data in informing one of the aspects of socialization in Weidman's model. On the other hand, lack of integration can also be explained by the fact that, as our data revealed, many students were struggling to adapt to the new norm for socialization in the online environment while the new norm was being co-created by instructors and students and continued to evolve. Learning, as a third component of socialization, reflects its ultimate purpose. As stated in Weidman's definition of socialization, through socialization, students "gain the knowledge, skills and values necessary for successful entry into a professional career" [6]. Our qualitative data demonstrated that with the generally decreased social interactions in the online environment, many students felt inadequate in both knowledge acquisition and professional development and were challenged by their lack of mental well-being for learning. On the other hand, many better appreciated the learning opportunities that involved synchronous interactions.

These patterns in the online socialization process provided evidence for the importance of social interactions to student learning, that is, social interactions with the internal reference groups - both peers and instructors - are critical for engineering students' social and academic development. The very unusual, "imposed" online learning environment during the pandemic seems to have offered an opportunity to test out the impact of inadequate social 
interactions on student learning. Our data revealed that the socialization patterns in the online environment removed important elements that help individual students learn. As the quotes cited earlier indicate, students felt that a lack of social interactions hindered their ability to persevere, limited their access to immediate or prompt feedback to help them learn, and kept them away from reference points they would need to self-assess their learning. These unfavorable situations help verify that learning not only concerns individuals' behavioral and cognitive processes but also constitutes a highly contextually situated social activity. As social cognitive learning theorists argue, individuals learn behaviours and cognitive strategies by observing the behaviours of others; thus, learning takes place through social interactions $[27,28]$.

Our findings suggest to us that educators should not take for granted the social environment for in-person learning before the pandemic. Rather, the social environment where students can interact with their peers and instructors at times of their choice offers many advantages for student learning. After the pandemic, educators should make greater efforts to leverage various opportunities for student socialization. When teaching in-person or hybrid courses in the future, instructors should consciously create or expand the socialization opportunities that are inherently embedded within these modes of delivery. They can do so by incorporating active learning activities into the classroom so that social interactions become part of the classroom dynamics. They can also "invert" the classroom by leaving the time for independent individual work outside the classroom while making the interactions with peers and instructors dominate the space of the classroom to form learning communities. In addition, the experiences of online teaching and learning during the pandemic helped boost the utilization of online venues for communication, as our findings showed. Therefore, instructors can also provide additional support for student socialization and learning by adding online discussion forums and text communication within in-person or hybrid courses when appropriate. These practices were already in place in some forms in engineering education practice prior to the pandemic. The conclusion of our study reinforces the value of those elements involving social interactions to student learning in engineering education settings.

Finally, this study reaffirmed to us that Weidman's socialization model was helpful to conceptualize our inquiry and interpret the results. Our findings corroborated the benefit of situating socialization in relation to the learning environment and outcome, which was student perception of learning in our study. Consistent with the model, we found that students' personal preferences impacted their socialization processes within the online environment and their overall perception of learning experiences. Our results also showed that Weidman's socialization model is useful to examine a broader scope of learning than the affective socialization outcomes studied in previous research using the model $[7,26]$. Thus, our study testifies the usefulness of theoretical perspectives to enhancing the scholarship of engineering education.

Looking forward, it is our hope that after the pandemic, engineering education will never have to be offered in such a confined environment as experienced during the pandemic. However, some of the issues encountered intensively this time will not diminish. These issues include interactions and socialization within the learning community, efficacy of online pedagogies, engineering communication strategies, and ultimately engineering students' knowledge acquisition, competency development and professional identity development in an increasingly digitalized world. Our findings in this paper provoked our deep thinking and may inspire other engineering education researchers to examine these issues further in the postpandemic era.

\section{References}

[1] J. Lee \& L. Martin, "Investigating Students' Perceptions of Motivating Factors of Online Class Discussions", International Review of Research in Open and Distance Learning, vol. 18, (5), pp. 148-172, 2017.

[2] L. Arasaratnam-Smith \& M. Northcote, "Community in Online Higher Education: Challenges and Opportunities", The Electronic Journal of e-Learning Volume 15 Issue 2, pp188-198, 2017.

[3] "Research and higher education in the time of COVID19", The Lancet, vol. 396, (10251), p. 583, 2020.

[4] S. H. Kyne and C. D. Thompson, "The COVID Cohort: Student Transition to University in the Face of a Global Pandemic," J. Chem. Educ., vol. 97, (9), pp. 33813385, 2020.

[5] D. Thibaut and K. T. Schroeder, "A case-based learning approach to online biochemistry labs during COVID19", Biochemistry and Molecular Biology Education, vol. 48, (5), pp. 484-485, 2020.

[6] J. C. Weidman, D.J. Twale, and E.L. Stein, "Socialization of Graduate and Professional Students in Higher Education: A Perilous Passage? ASHE-ERIC Higher Education Report, Volume 28, Number 3. Jossey-Bass Higher and Adult Education Series", ASHE-ERIC Higher Education Reports, 2001.

[7] D. J. Twale, J. C. Weidman \& K. Bethea, "Conceptualizing Socialization of Graduate Students of Color: Revisiting the Weidman-Twale-Stein Framework", The Western Journal of Black Studies, vol. 40, (2), pp. 80-94, 2016.

[8] Weidman, John C. "Undergraduate Socialization: A Conceptual Approach", pp. 289-322 in John C. Smart (Ed.), Higher Education: Handbook of Theory and Research, Vol. V. New York: Agathon Press, 1989. 
[9] J. D. Cochran et al, "The Role of Student Characteristics in Predicting Retention in Online Courses", Research in Higher Education, vol. 55, (1), pp. 27-48, 2013.

[10] M. Öztok, "Cultural ways of constructing knowledge: the role of identities in online group discussions," International journal of computersupported collaborative learning, vol. 11, no. 2, pp. 157-186, 2016.

[11] C. Stöhr, C. Demazière, and T. Adawi, "The polarizing effect of the online flipped classroom," Computers and education, vol. 147, p. 103789-, 2020.

[12] J. Martínez-Cerdá, J. Torrent-Sellens \& I. GonzálezGonzález, "Promoting collaborative skills in online university: Comparing effects of games, mixed reality, social media, and other tools for ICT-supported pedagogical practices", Behaviour \& Information Technology, 37(10-11), 1055-1071. 2018.

[13] R.G. Qiu, “A systemic approach to leveraging student engagement in collaborative learning to improve online engineering education", International Journal of Technology Enhanced Learning, 11(1), 1-19, 2019.

[14] R.M. Davison, N. Panteli, A.M. Hardin, \& M.A. Fuller, "Establishing effective global virtual student teams", IEEE Transactions on Professional Communication, 60(3), 317-329, 2017.

[15] P. Slagter van Tryon J. \& M. J. Bishop, "Theoretical foundations for enhancing social connectedness in online learning environments", Distance Education, vol. 30, (3), pp. 291-315, 2009.

[16] Y. Lan et al, "Comparing the social knowledge construction behavioral patterns of problem-based online asynchronous discussion in e/m-learning environments," Computers and Education, vol. 59, (4), pp. 1122-1135, 2012.

[17] J. Decker and V. Beltran, "Students' Sense of Belonging in Online Classes: Does Age Matter?" International Journal of Online Pedagogy and Course Design, vol. 6, (3), pp. 14-25, 2016.

[18] NU.CEPAL, Education in the time of COVID-19, 2020 UNESCO. Available as of April 20, 2020 from https://www.cepal.org/en/publications/45905education-time-covid-19

[19] E. H. J. Yew \& J. Y. Yong. "Student perceptions of facilitators' social congruence, use of expertise and cognitive congruence in problem-based learning," Instructional Science, Vol. 42, No. 5 (September 2014), pp. 795- 815, 2014.

[20] K. Otani, B. Kim, \& J. Cho. "Student evaluation of teaching (SET) in higher education: How to use SET more effectively and efficiently in public affairs education," Journal of Public Affairs Education, 18(3), 531-544, 2012.

[21] Cambridge University, Guides to teaching in 2020-21. Available as of April 20, 2020 from https://www.cctl.cam.ac.uk/teaching-2020-21/guides

[22] Harvard University, Best Practices: Online Pedagogy, v1. Available as of April 20, 2020 from https://teachremotely.harvard.edu/best-practices-old

[23] McGill University. Planning for a Remote Fall Semester, Survey results. Available as of April 20, 2020 from https://www.mcgill.ca/studentservices/aboutus/covid-19-student-survey-results/planning-remotefall-semester-survey-results

[24] University of Waterloo. Spring Student Survey. Available as of April 20, 2020 from https://uwaterloo.ca/coronavirus/sites/ca.coronavirus/fi les/uploads/files/spring 2020 student survey results final final-ua.pdf

[25] C. Naughton, J. Smeed, \& J. Roder. "Delimiting the prospect of openness: An examination of initial student approaches to e-learning." International Review of Research in Open and Distance Learning, 12(2), 103$121,2011$.

[26] J.C. Weidman \& E.L. Stern, "Socialization of Doctoral Students to Academic Norms" Research in Higher Education. Vol 44, No. 6, 2003.

[27] A. Bandura, "Human agency in social cognitive theory," American Psychologist, 44, 1175-1184, 1989.

[28] M.G. Green \& J.A. Piel, Theories of human development: A comparative approach (second ed.), New York: Routledge, 2009. 